\title{
Labour Immigration after Brexit: Questions and Trade-offs in Designing a Work Permit System for EU Citizens
}

\author{
Madeleine Sumption, University of Oxford
}

After several years in which the scale of EU migration has become an increasingly salient question in the migration debate, the June 2016 vote to leave the EU raises the possibility of significant change to UK migration policy.

Since work is the main reason for EU migration to the UK, labour migration policies after Brexit are a particularly important item on the list of possible policy changes. There are several different labour migration models that could potentially be used after Brexit, from modified versions of free movement to work permit systems of different shapes and sizes. Policy choices in this area will require the government to consider a a host of sometimes often conflicting objectives and, as this paper illustrates, there is no single, 'optimal' policy design.

If the government decides to end free movement and implement a work-permit system, this decision will be only a small part of the process of designing any new post-Brexit labour migration system. After all, every country in the OECD has a work permit system of some kind, but many take radically different approaches to labour migration-from the liberal Swedish approach of admitting non-EU citizens with a job offer in almost any occupation to the UK system in which only about one fifth of employee jobs meet the main skill and salary criteria that will apply from April 2017 (Vargas-Silva, 2016a).

This paper examines a selection of the key questions the government would face designing a work permit system after Brexit. Specifically, looks at:

- Which jobs are eligible for labour migration, particularly in the low- and middle-skilled echelons of the labour market that are currently ineligible for work permits under arrangements in place for non-EU citizens.

- Whether there are nationality-specific eligibility criteria-for example, whether EU and non-EU citizens face the same rules, and/or whether there are any bilateral agreements with particular EU countries.

- To what extent labour migration is expected to be temporary vs. lead to permanent settlement, and what other rights labour migrants have, such as the ability to bring family members to the UK.

- What trade-offs the government will face in implementing these rules, including tensions between the desire to design a 'tailored' set of rules that appears responsive to complex policy objectives in different industries and occupations, and the desire to maintain simple and easily enforceable labour migration rules.

As the government makes decisions about what kind of labour migration system to operate for EU citizens after Brexit, it faces a set of trade-offs. On one hand, Government has made a clear commitment to reduce migration, and this commitment will presumably be an important organising principle for labour migration policy decisions in the coming years. Low and middleskilled work is most likely to be the main target of any policies to reduce EU labour migration.

On the other hand, the Government also has other objectives, including the desire to improve the employment prospects of existing UK residents, give employers access to skills and labour where doing so is considered most beneficial, support broader policy goals outside of immigration, and negotiate a mutually beneficial economic relationship with the European Union. Some of these objectives will conflict, requiring judgments about what to prioritise and how. This process is not a simple accounting exercise but requires important subjective and 
political judgments about who-and particularly which industries-will win or lose from policy decisions.

This paper begins by addressing how to think through which occupations would be eligible for labour immigration if free movement comes to an end-particularly in low- and middle-skilled jobs where there are few obvious statistical metrics for deciding where such workers should be admitted (if they are admitted at all). It then discusses the possibility of different eligibility criteria for different workers, focusing on policies that discriminate by nationality. The following section examines the dynamics of temporary vs. permanent work permit programmes. The paper concludes by examining the trade-off between fine-tuning and simplicity, arguing that the government may face choices between the ability to tailor immigration policy to government objectives outside of immigration, and the potential benefits of maintaining a simpler, more uniform and easily enforceable set of rules that apply to workers and employers across the board.

\section{Which jobs will be eligible for labour migration?}

Arguably the key question for the UK government when designing any post-Brexit work permit system is which jobs would be eligible. In theory, the government could make all occupations eligible for work permits. This is the Swedish model of labour migration, although it is quite unusual by international standards (Ruhs, 2013; OECD, 2011). However, work permit systems in high-income countries typically restrict eligibility by occupation, with more liberal policies towards applicants for skilled jobs (Ruhs 2013). A key reason for this is that the evidence on the potential economic benefits of migration is much more clear-cut in the case of skilled migration (see, for example, Ruhs (2015) on the labour market effects of migration and Vargas-Silva (2016b) on the fiscal impacts). Low-skilled worker programmes are still quite common, although they tend to be more restrictive-often limited to specific types of work and often providing no or limited routes to permanent settlement or options for family unification (Ruhs, 2013).

Any labour migration system is likely to allow migration into the highest skilled jobs, such as high-paid professional positions in finance or engineering. Where the cut-off between 'skilled' and 'not skilled' should lie is not objectively obvious. For example, skilled work visas in the United States and the UK must generally be for graduate-level jobs (those normally requiring a bachelor's degree - such as engineers or doctors), while Australia, New Zealand, Canada, and Norway define 'skilled' as including many tradespeople and people with sub-degree vocational qualifications (such as plumbers or paramedics). These distinctions aside, the key policy question in high-skilled jobs in any post-Brexit work permit system is what the application process looks like-for example, whether it requires employers to pay fees or attempt to recruit UK workers before sponsoring a worker from overseas.

The area where Brexit could potentially see the greatest shift from the status quo, however, is in jobs that are not classified as highly skilled. Under the current classifications used in the UK immigration system, these range from skilled trades occupations in the construction industry to relatively low-paid work in social care, hospitality or fruit picking, and employ the majority of EU citizens currently working in the UK (Vargas Silva, 2016a). The government will need to decide how much - if any - of this demand it will continue to satisfy through EU migration after Brexit. 
If low and middle-skilled labour immigration are to be restricted, which types of work should be prioritised? To address this question it is worth reviewing why low-skilled worker programmes exist at all.

In low-wage work, the most common argument for facilitating labour migration is that there are certain jobs in which it is difficult to recruit at the wages and conditions on offer. Commonly cited examples include agricultural labour, hospitality and social care (MAC, 2014). In theory, employers without access to migrant labour could attract local workers into the profession with higher wages; restructure the work to rely on a smaller number of more skilled recruits; or reduce the need for staff by relying more on technology (Ruhs, 2010). However, these strategies are likely to increase costs and the time required for recruiting, and if the business is operating in a competitive market the employer may be under pressure to keep prices low relative to domestic or international competitors.

The extreme cases, in some respects, is the horticultural industry, which in many countries relies heavily on migrant workers, particularly for harvesting crops during peak periods that require much larger worker numbers at a specific place and time (Geddes and Scott, 2010). Without a low-wage labour force, some types of agricultural production would become more difficult to sustain (MAC, 2013). In these cases, the industry may simply shrink without access to migrant workers.

Whether or not this is a desirable outcome is a matter of judgment and will depend on the specific case. In agriculture, for example, the government could decide that the country should simply import more food, particularly the most labour-intensive produce. On the other hand, it may decide that a 'home-grown' food supply is beneficial for political or geopolitical reasons (such as 'food security'). Low-skilled worker programmes are in some respects a recognition of the notion that - at least in certain cases-governments may consider it desirable to use migration to support a low-wage industry despite its reliance on migrant workers. These considerations reach well beyond the traditional domain of immigration policymakers.

Another example of an activity that has particular political significance is nursing and adult social care. EU workers have played a significant role in social care in recent years, as policies towards care workers from non-EU countries have become more restrictive (Franklin and Brancati, 2015). If migrant workers willing to do difficult work at relatively low rates of pay enable care providers to keep prices low, this may increase the availability of a service on which vulnerable people rely. It may also reduce costs to taxpayers, since a substantial share of social care is local-authority funded (LaingBuisson, 2015). However, the government could instead choose to spend much more on social care and attempt to transform it into a higher-wage, higher-productivity occupation-another decision that stretches well beyond the remit of immigration policymakers. Similar arguments could be made in other sectors such as construction, which the Communities and Local Government Secretary Sajid Javid recently suggested would continue to require migrant labour after Brexit (Parker and Allen, 2016); this is another sector that has seen a rapidly growing EU workforce over the past 15 years.

A completely different rationale that is often advanced in favour of low-skilled worker programmes is to reduce incentives for illegal working. The argument is that if employers have access to a legal workforce they will be less willing to employ people without authorisation (Hanson, 2009; Duvell, 2011). Preventing illegal employment has been a large part of the discussion about low-skilled workers in the United States, for example (American Immigration Council, 2013), and was also part of the rationale behind the worker schemes in food processing and hospitality in the UK during the early 2000s (Clarke and Salt, 2003).

In the post-Brexit environment, unauthorised employment could become a particular concern, since the combination of some industries reliance on EU workers, well-established recruiting 
channels and social networks, and the ease of travel to the UK could facilitate recruitment into low-wage jobs that are not eligible for work permits. Non-compliance with work regulations before EU enlargement in 2004 has been documented elsewhere (Ruhs, 2006). However, it is very difficult to know to what extent providing legal routes for low-skilled migration is an effective a tool to discourage illegal working (or whether it simply adds to the low-wage migrant workforce), since data on unauthorised employment is elusive.

Given how complex and varied these different considerations are, it is not surprising that there are few obvious statistical metrics for prioritising different kinds of immigration in the low- and middle-skilled echelons of the labour market. The case for maintaining vs. restricting labour migration in different industries and occupations will depend on a host of factors, such as whether there are feasible alternatives to EU migration (e.g. labour-saving technology), and what the social or economic consequences would be of allowing the industry and its workforce to shrink. It will involve political considerations that reach well beyond immigration policy, many of which are by no means easy.

Should the government prioritise the continued existence of labour-intensive horticulture in the UK, or import more produce from abroad? Should it dedicate significantly more funding to supporting a higher-skilled, higher-wage adult social care workforce, or facilitate migration as a way to meet growing demand for low-cost care? How should considerations such as these be weighted as part of an overarching strategy to reduce migration? These are essentially political questions rather than economic ones, although they have implications for the operational complexity of the immigration system that are discussed further in the conclusion.

\section{Which workers are eligible? Nationality-specific provisions}

Another important question in any post-Brexit work permit system is whether rules with be the same or different for EU vs. non-EU citizens. On one hand, an end to free movement could mean that uniform work-permit rules are applied to people of all nationalities. However, this is by no means guaranteed: nationality-specific rules are quite common in immigration systems, including the UK.

For example, the UK's Youth Mobility Scheme visa involves a series of reciprocal agreements that allow 18-30 year olds from Australia, Canada, Japan, Monaco, New Zealand, Hong Kong, Korea and Taiwan to work in the UK for up to 2 years, with similar privileges for British citizens in those countries. Australia has similar arrangements with 18 other countries. The United States created a special work permit for Australian nationals allowing them to bypass numerical limits on work permits, following negotiations on a free trade agreement in the early 2000s (Sumption, Papademetriou and Flamm, 2013). Other country-specific programmes, such as New Zealand's seasonal worker scheme for people from the Pacific Islands, have development objectives - to encourage the transfer of skills and (particularly) remittances to poorer neighbouring countries.

In the context of Brexit, a key reason for EU-specific rules would be to facilitate negotiations on the UK's future trading relationship with the EU. There could also be a role for bilateral agreements with specific EU countries where there are particularly significant bilateral migration flows, such as Poland or Spain. The European Commission may oppose bilateral dealmaking, especially while overall UK-EU negotiations are still ongoing, although other EU countries do have a range of bilateral arrangements with non-EU countries (EMN, 2011), so such a move would not be unprecedented in principle.

On the other hand, a drawback of country-specific rules is that they add complexity to the immigration system, making it more difficult for the Home Office and employers to implement. From the employer perspective, the candidate's nationality is likely to be less important than 
their skills, which means that nationality-specific rules may create arbitrary restrictions on which qualified candidates can be hired. In addition, visa rules that vary by nationality may require employers to offer different employment conditions to staff members doing the same job (for example, different contract durations or rights to bring dependants), and may therefore be unpopular in the workplace.

\section{How long can workers stay?}

Work permit systems around the world vary widely in the ease with which workers can gain permanent status and citizenship. Some countries, such as Canada and some of the Australian visa routes, offer permanent residence immediately, at least to skilled workers. Others offer temporary visas that can be renewed and lead to permanent residence a few years later; there may be separate, more demanding, criteria for permanent residence than for initial entry. For example, all EU countries except for the UK, Ireland and Denmark, participate in the 2003 European Directive that requires them to grant long-term status to non-EU citizens after five years of residence. However, some work permit programmes are strictly time-limited; workers are expected to return home after the permitted period expires and are not allowed to apply for permanent settlement (though this may be possible if they first switch onto another visa type). Strictly temporary work permits are most common in programmes for low-skilled workers (Ruhs, 2013; OECD, 2014). These programmes often also restrict other rights, such as the ability to bring family members.

While EU citizens currently have the right to stay permanently in the UK, there is already significant temporary migration from EU countries: an estimated 125,000 EU citizens came to work in the UK for between 1 and 12 months in 2014 (ONS, 2016). Under a post-Brexit work permit system, the government would need to decide how easy it would be to transition to permanent residence.

This decision involves important trade-offs. On one hand, policymakers often favour strictly temporary programmes when there is uncertainty about the long-term demand for particular groups of workers or about their potential to integrate successfully in the long run-including after they are no longer employed in the specific job for which they were recruited. Temporary migration may also be seen as a way to reduce the fiscal costs of low-skilled migration (such as the cost of schooling for children), by preventing family unification. In some cases, the demand for labour is itself inherently temporary due to seasonal variations in demand in industries such as hospitality or horticulture, making a short-term visa a natural choice.

However, temporary migration programmes also have drawbacks. By design, they discourage social and economic integration, processes that take place over time as migrants improve their language skills or develop social connections and local knowledge. They make it harder for employers to retain workers who have built up skills over time (from specialised knowledge of the firm's products to an understanding of health and safety procedures), instead relying on a constantly rotating pool of new recruits who will take some time to settle in. Temporary workers often have more limited rights (Ruhs, 2013), including the right to switch between employers, making them more vulnerable to exploitation. Finally, it may be difficult to enforce return, especially if the job itself is not inherently temporary.

\section{Conclusion: how complex should a new immigration system be?}

One of the trade-offs the government faces in deciding on the scope of work permit programmes is between the ability to tailor policies to different government objectives vs. create a system that applies a transparent and simple set of rules more uniformly. The argument for a certain degree of fine-tuning is that the government can usefully put immigration policy at the service 
of other government objectives-for example, using it to build skills or supply labour to particular industries or reduce costs in the public sector.

The argument against such tailoring is that it makes the immigration system more complex and thus more difficult for the government to manage and enforce. An immigration system with complex industry-specific rules and quotas, with different kinds of authorisation required depending on the nature of the work, would require greater resources in order to police the boundaries between different categories.

An accompanying challenge with complex, industry-specific rules is how to determine where to facilitate migration and where to restrict it. Because of the complexity of the different arguments for different types of 'need' for workers below the ranks of the highest skilled, there is no single, objective way to do this.

Deciding whether it makes sense to facilitate migration into a given industry will mean balancing many different considerations. These include, for example, whether alternatives to migration such as labour-saving technology are realistic; whether there are circumstances under which more British workers could be encouraged to do the work; or whether the industry is considered 'strategically important' - a concept that is difficult to define in practice. ${ }^{1}$ Other important considerations include government objectives other than immigration, such as how it plans to meet demand for adult social care or staff the NHS, what role it envisages for an agricultural industry in the UK and, more broadly, whether it wants to use immigration as part of a broader industrial strategy to support particular parts of the economy.

The lack of simple statistical metrics for prioritising different kinds of immigration in the lowand middle-skilled echelons of the labour market makes it inevitable that political judgment will play a strong role. Indeed, there is a risk that when developing a system with widely varying industry-specific rules, the government will come under pressure from organised interests to add further exemptions for political reasons, rather than relying on 'hard evidence' or making decisions based on systematic consideration of the government's overall policy priorities. However, it is possible to assess these qualitative factors systematically, as the Migration Advisory Committee has done in the past when examining questions such as whether there are shortages in particular occupations or what would be the impact of closing the Seasonal Agricultural Workers Scheme in 2013. If the policy objectives are sufficiently clear, the same approach could be taken to a wider range of occupations and industries.

\section{Timing and transitions}

In addition to these policy design questions, there are complex operational questions about the timing of policy changes. In particular, the government will need to ensure that before any new work permit system is introduced, the necessary policy guidance and visa-processing staff are in place. If migration policies end up playing a significant role in EU negotiations, it may be difficult to develop and consult on the relevant rules and processes long in advance of the conclusion of a post-Brexit UK-EU cooperation agreement, raising the question whether transitional rules will be required in the immediate aftermath of a UK-EU deal. (There could also be a role for transitional migration rules for other reasons, such as to allow employers to adjust more gradually to the significant change that ending free movement would bring.) The operational complexity of introducing an entirely new work permit system could be compounded by the large-scale challenge of processing residence applications for EU citizens already living in the UK before Brexit who are expected to retain their residence rights and will

\footnotetext{
1 These are the main criteria the Migration Advisory Committee uses to assess whether it is 'sensible' to add an occupation to the UK's shortage occupation list; the criteria are evaluated primarily using qualitative rather than statistical evidence (MAC 2011).
} 
need documentation to prove it, if free movement comes to an end (Migration Observatory, 2016).

This paper is based on a Migration Observatory report published in January 2017 with the support of Deloitte. Thanks to Martin Ruhs, Maria Vincenza Desiderio, Jurga McCluskey, Jonathan Portes, and an anonymous reviewer for comments on earlier drafts.

\section{References}

American Immigration Council. 2013. Built to Last: How Immigration Reform Can Deter Unauthorized Immigration. Washington, DC: American Immigration Council.

Clarke, James and John Salt. 2003. Work permits and foreign labour in the UK: a statistical review. Labour Market Trends November 2003.

Duvell, Franck. 2011. Paths into Irregularity: The Legal and Political Construction of Irregular Migration. European Journal of Migration and Law, 2011, 13.3: 275-295.

Franklin, Benjamin and Cesira Urzi Brancati. 2015. Moved to care: the impact of migration on the adult social care workforce. London: International Longevity Centre. Available online.

Geddes, Andrew and Sam Scott. 2010. UK food businesses' reliance on low-wage migrant labour: A case of choice or constraint? In Who Needs Migrant Workers? Labour shortages, immigration, and public policy, edited by Martin Ruhs and Bridget Anderson. Oxford: Oxford University Press.

Hanson, Gordon. 2009. The Economics and Policy of Illegal Immigration in the United States. Washington, DC: Migration Policy Institute.

LaingBuisson. 2015. Care of Older People. London: LaingBuisson.

Migration Advisory Committee. 2011. Skilled Shortage Sensible: Full review of the recommended shortage occupation lists for the UK and Scotland. London: Migration Advisory Committee.

Migration Advisory Committee. 2013. Migrant seasonal workers. London: MAC.

Migration Observatory. 2016. Here today, gone tomorrow? The status of EU citizens already living in the UK. Oxford: Migration Observatory.

Office for National Statistics. 2016. Short-term international migration annual report: mid-2014 estimates. London: ONS. Available online.

European Migration Network. 2011. Temporary and Circular Migration: empirical evidence, current policy practice and future options in EU Member States. Brussels: European Migration Network.

OECD. 2011. Recruiting migrant workers: Sweden 2011. Paris: OECD.

Organisation for Economic Cooperation and Development. 2014. International Migration Outlook 2014. Paris: OECD. 
Parker, George and Kate Allen. 2016. UK still open to European builders after Brexit, says Javid. Financial Times.

Ruhs, Martin. 2006. Greasing the wheels of the flexible labour market: East European labour immigration in the UK. University of Oxford, COMPAS working paper no 38.

Ruhs, Martin. 2013. The price of rights: regulating international labour migration.

Ruhs, Martin. 2015. The Labour Market Effects of Immigration. Oxford: Migration Observatory.

Sumption, Madeleine, Demetri Papademetriou and Sarah Flamm. 2013. Skilled Immigrants in the Global Economy: Prospects for International Cooperation on Recognition of Foreign Qualifications. Washington, DC: Migration Policy Institute.

Vargas-Silva, Carlos. 2016a. Potential implications of admission requirements for EU nationals coming to the UK. Oxford: Migration Observatory.

Vargas-Silva, Carlos. 2016b. The fiscal impact of immigration in the UK. Oxford: Migration Observatory. 